\title{
Recent updates on the basic mechanisms and pathogenesis of inflammatory bowel diseases in experimental animal models
}

\author{
Emiko Mizoguchi ${ }^{1,2}$, Daren Low ${ }^{3}$, Yui Ezaki ${ }^{1}$, Toshiyuki Okada ${ }^{1}$ \\ ${ }^{1}$ Department of Immunology, Kurume University School of Medicine, Kurume, Japan; ${ }^{2}$ Department of Molecular Microbiology and \\ Immunology, Brown University Warren Alpert Medical School, Providence, RI, USA; ${ }^{3}$ Crohn's \& Colitis Society of Singapore, Singapore
}

The specific pathogenesis underlining inflammatory bowel disease (IBD) is very complicated, and it is further more difficult to clearly explain the pathophysiology of 2 major forms of IBD, Crohn's disease (CD) and ulcerative colitis (UC), and both disorders affect individuals throughout life. Despite every extensive effort, the interplay among genetic factors, immunological factors, environmental factors and intestinal microbes is still completely unrevealed. Animal models are indispensable to find out mechanistic details that will facilitate better preclinical setting to target specific components involved in the pathogenesis of IBD. Based on many recent reports, dysbiosis of the commensal microbiota is implicated in the pathogenesis of several diseases, not only IBD but also colon cancer, obesity, psoriasis as well as allergic disorders, in both human and animal models. Advanced technologies including cell-specific and inducible knockout systems, which are recently employed to mouse IBD models, have further enhanced the ability of developing new therapeutic strategies for IBD. Furthermore, data from these mouse models highlight the critical involvement of dysregulated immune responses and impaired colonic epithelial defense system in the pathogenesis of IBD. In this review, we will explain from the history of animal models of IBD to the recent reports of the latest compounds, therapeutic strategies, and approaches tested on IBD animal models. (Intest Res 2020;18:151-167)

Key Words: Inflammatory bowel disease; Animal models; Knockout mice; Susceptibility genes; Signal transduction

\section{INTRODUCTION}

Inflammatory bowel disease (IBD) is an intestinal inflammatory condition that affects more than 2 million and 0.2 million people in the United States and Japan, respectively. Initially, the 3 major genetically manipulated mouse models of spontaneous intestinal inflammation including interleukin-10 knockout (IL-10 KO), IL-2 KO and T cell receptor alpha chain (TCR $\alpha$ )

Received November 21, 2019. Revised January 18, 2020.

Accepted February 10, 2020.

Correspondence to Emiko Mizoguchi, Department of Immunology, Kurume University School of Medicine, 67 Asahi-machi, Kurume, Fukuoka 830-0011, Japan. Tel: +81-942-31-7551 Fax: +81-942-31-7699 E-mail: emizoguchi@ med.kurume-u.ac.jp
KO mice, were established in $1993 .^{1-3}$ Since then, experimental murine models of intestinal inflammation that mimic IBD have become increasingly common over the last 2.5 decades. These include experimentally induced and genetically altered models as well as spontaneously developed intestinal inflammatory models. ${ }^{4-6}$ Currently, so many different kinds of spontaneous IBD animal models, which were generated by genetically engineered technologies, have emphasized the presence of extremely complicated imbalance of internal/external factors during the development of IBD. ${ }^{4.7}$ In particular, a disturbance to gut microbiota homeostasis, so called dysbiosis, has been implicated a wide range of diseases including not only IBD but also obesity, allergic disorders, diabetes mellitus, autism spectrum disorders, and colon cancer. ${ }^{7-9}$ Therefore, dysbi- 
osis should be always taken into consideration when we discuss the complicated pathogenesis of several disorders. Various factors including genetic factors, immunological factors, environmental factors, and diet are highly involved in the formation of gut dysbiosis. ${ }^{7}$ To closely understand the interplay of the above factors, animal models of IBD are indispensable. So far, at least 66 different kinds of animal models of IBD have been established, and these are classified into chemically induced, adaptive cell transfer, congenital mutant and genetically engineered models. ${ }^{10}$ Furthermore, recent advances on genetically engineered techniques allowed us to utilize cell-specific/inducible $\mathrm{KO}$ as well as knock-in mouse systems in IBD studies. ${ }^{410}$

Based on the result of human genome-wide association studies (GWASs), several IBD susceptibility genes have been identified so far. ${ }^{11-14}$ In particular, IL-10 receptor and its signaling components seem to be very critical in regulating intestinal homeostasis and immunity, and polymorphisms of those genes in innate immune cells are associated with dysregula-

\begin{tabular}{|c|c|c|}
\hline Conventional KO & Cell specific KO & Inducible KO \\
\hline $\begin{array}{l}\text { Ahr KO (ROR+/-) } \\
\text { ATF4 KO }{ }^{14} \\
\text { A2O KO } \\
\text { Bach2 KO } \\
\text { Cbl-b KO } \\
\text { Cgamma KO } \\
\text { Gai2 KO } \\
\text { GPX1/2 dDK } \\
\text { IL1Ra KO } \\
\text { IL2 KO } \\
\text { IL2Ra KO } \\
\text { IL2Rß KO } \\
\text { IL10 KO } \\
\text { Itch KO } \\
\text { K8 KO } \\
\text { Lcn2/lL10 KO } \\
\text { Mdr1a KO } \\
\text { Muc2 KO } \\
\text { Nr2f6 KO } \\
\text { Rhbdf2 KO } \\
\text { SHIP KO } \\
\text { TCRa KO } \\
\text { TLR5 KO } \\
\text { WASP KO }\end{array}$ & 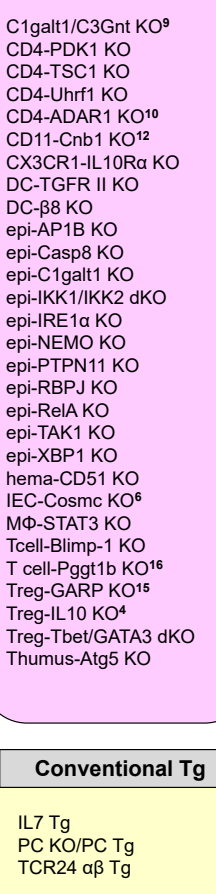 & \begin{tabular}{l} 
Dominant negative \\
CD4-TGFR II Dn \\
Epi-N cadherin Dn \\
Mutagen induced \\
Gimap5 \\
Yipf6 \\
\multicolumn{1}{|c|}{ Knock in } \\
Gp130 Ki \\
P110ס Ki \\
TNF(ARE) Ki
\end{tabular} \\
\hline
\end{tabular}

tion of mucosal immune tolerance and development of early onset of IBD. ${ }^{14-16}$ To analyze animal models that manipulate the IBD susceptibility genes may strongly enhance our understanding of their roles in IBD pathogenesis. Furthermore, experimental models of IBD have provided a way to closely dissect mechanisms of understanding the pathogenesis of IBD, which will be associated with developing multiple and critical inventions for IBD therapeutic strategies (e.g., small molecules, biologics) currently.

\section{MOUSE MODELS OF IBD}

Currently available mouse models of IBD have been divided into the following 4 categories as shown below.

\section{Genetically Engineered Murine Models of IBD}

Recent advances on genetic engineering technologies allowed us to analyze the influences of overexpression or deficiency of particularly interesting genes during the development of IBD.

Fig. 1. Mouse models of IBD with gene targeting strategies. As previously described, mouse models of IBD has been classified into 9 groups based on the gene targeting strategies, which include conventional/cell-specific transgenic (Tg), conventional/ cell-specific knockout (KO), inducible KO (iKO), inducible Tg (iTg), dominant negative (Dn), knock-in (KI), mutagen-induced and innate models. AGR2, anterior gradient protein 2 homolog; Ahr, aryl hydrocarbon receptor; ATF4, activating transcription factor 4; Bach2, BTB domain and CNC homolog 2; Blimp, B-lymphocyte-induced maturation protein; C1galt1, core 1 synthase, glycoprotein- $\mathrm{N}$-acetylgalactosamine 3-beta-galactosyltransferase 1; Casp8, caspase 8; CD4, CD4 positive T cells; Cgamma, common gamma; $C P X$, carboxypeptidase $X_{;}$dKO, double KO; Epi, epithelial cells; GARP, glycoprotein-A repetitions predominant protein; GATA3, GATA binding protein 3; Gimap5, GTPase, IMAP family member 5; IEC, intraepithelial lymphocytes; IKK, I kappaB kinase; IL, interleukin; IRE, inositol-requiring enzyme; Itch, itchy E3 ubiquitin protein ligase; Lcn2, lipocalin-2; Mdr1a, multidrug resistance protein 1a; M $\varphi$, macrophages; Muc2, mucin 2; NEMO, NF-kappa-B essential modulator; NFATc, nuclear factor of activated T cells; Nr2f6; nuclear receptor subfamily 2, group $F_{\text {, }}$ member 6; PC, proprotein convertases; PDK1, 3-phosphoinositide-dependent protein kinase 1; Pggt1b, protein geranylgeranyltransferase type 1 subunit beta; PTPN11, tyrosine-protein phosphatase non-receptor type $11 ; R A G$, recombination-activating gene; RBP, retinol-binding protein; Rhbdf2, rhomboid 5 homolog 2; ROR, RAR-related orphan receptor; SHIP, SH-2 containing inositol 5 polyphosphatase; SOCS1, suppressor of cytokine signaling 1; STAT3, signal transducer and activator of transcription 3; TAK1, transforming growth factor-beta-activated kinase $1 ; T C R$, T cell receptor; TLR, Toll-like receptor; TGFR, transforming growth factor beta receptor; TNFSF, TNF superfamily member 15; Treg, regulatory T cell; WASP, Wiskott-Aldrich syndrome protein; Yipf6, Yip1 domain family member 6; B, B cells; DC, dendritic cells; epi, epithelial cells; Foxp3, regulatory T cells. Modified from Mizoguchi A, et al. J Pathol 2016;238: 205-219. ${ }^{4}$ 
Based on the gene construction strategies, genetically engineered murine models of IBD are classified into 9 groups, which includes conventional transgenic ( $\mathrm{Tg}$ ) or KO mice models, dominant negative Tg models, cell-specific Tg or KO models, inducible KO models, knock-in models, innate models, and mutagen-induced models (Fig. 1). In particular, conventional KO mice, which are genetically engineered to lack a particular gene of interest in all cell types, are commonly used to study the pathogenic/regulatory factors during the development of spontaneous chronic colitis. ${ }^{1-4}$ It is dispensable to utilize genetically engineered mouse models of IBD for understanding the pathogenesis of IBD and these models have been providing important insights into the pathogenic mechanisms of chronic colitis development. Although the intestinal inflammation seen in these models does not exactly replicate human IBD and cannot be a complete surrogate for the human disease, some characteristically pathological features are relatively reproducible and open for investigation. ${ }^{17}$

Cell-specific KO (conditional KO) mouse is made by crossing the flox mouse (which gene loci sandwiching the target gene region with the Cre recombinase target sequence loxP) and the mouse with expressing tissue/cell-specific Cre recombinase. As a result, a particular target gene can be deleted in tissues/cells that form specific organs. Inducible KO mice can reversibly control the expression of the gene of interest. Conventional Tg mice overexpress all cells by introducing the target gene. In contrast, cell-specific Tg mice can be overexpressed in specific cells and organs by using viral vectors or electroporation (Fig. 1).

Dominant negative $\mathrm{Tg}$ mice are genetically engineered to overexpress non-functional proteins that interfere with the normal function of the target protein, whereas knock-in mice have a mutation in the gene of interest including the IBD susceptibility genes. The innate model has a lack of specific genes that cause immunodeficiency. Finally, in the mutagen-induced model, genetic variation is induced by N-ethyl-N-nitrosourea (ENU), a highly potent mutagen. In summary, these genetically engineered mouse strains are very useful for analyzing gene functions in elucidating the complex IBD mechanisms.

\section{Chemically Induced IBD Models}

Currently, chemically induced colitis models belong to one of the most commonly used mouse IBD models since the onset of inflammation is immediate and the procedure is generally straightforward. ${ }^{18}$ Chemically induced colitis models are suitable for dissecting the pathogenic/regulatory components during different phases of colitis, such as acute, recovery and chronic phases. ${ }^{19}$ These models enable us to pick up some novel genes that are highly involved in IBD susceptibility, and also to identify some immunological/biological mechanisms during the development of acute/chronic colitis. ${ }^{18,19}$ Oral administration of dextran sodium sulfate (DSS), induces colonic epithelial injury and has been widely used as not only acute but also chronic colitis model, ${ }^{19,20}$ which is useful for assessing mechanism of wound healing process and inflammation of associated epithelial homeostasis. However, chemically induced colitis models need to optimize concentration of chemicals depending animal facilities. In addition, colitis induced by some chemicals by single administration usually shows acute colitis features and self-limiting without any treatment.

One cycle of 3\% to 5\% DSS administration for 4-7 days, followed by regular water, results in acute injury with partial crypt depletion on the distal segment of colon. The colon shows multiple and skipped mucosal erosive lesions with mixed inflammatory cell infiltration of mononuclear/polymorphonuclear cells. ${ }^{20}$ Since DSS termination induces the recovery of colonic mucosa gradually, this colitis model has been frequently used for studying epithelial wound healing during the recovery phase. ${ }^{19}$ After the late recovery phase, macrophages and $\mathrm{CD} 4^{+} \mathrm{T}$ cells become prominent in areas of wound healing in the basal portion of the lamina propria. ${ }^{19}$ However, DSS-induced acute colitis can be still induced in the absence of acquired immunity as severe combined immunodeficiency (scid) mice are also susceptible. Therefore, this colitis is a simple model of acute chemical injury rather than chronic inflammation, and researchers should not use it as a model for human UC. Similar to the DSS colitis model, rectal administration of hapten reagent 2,4,6-trinitrobenzene sulfonic acid (TNBS) with ethanol is widely utilized as a model for intestinal inflammation in rat and mouse. ${ }^{21,22}$ This TNBS-colitis model has many features of CD in humans, including severe transmural colitis, which is induced by Th1/Th17-mediated immune responses. ${ }^{23}$ In contrast, rectal administration of ethanol suspended oxazolone, another haptenating agent, leads to an IL-4 driven Th2-type colitis, which is limited to the distal part of the colon with relatively superficial ulceration of epithelium. ${ }^{24}$

In 1978, MacPherson and Pfeiffer ${ }^{25}$ found that administration of $3 \%$ to $5 \%$ acetic acid induces acute colitis with initial epithelial necrosis and edema in rats. Similarly, administration of acetic acid also causes colonic epithelial destruction followed by inflammatory cell infiltration in mice. ${ }^{26}$ In contrast, 
subcutaneous administration of indomethacin, a NSAID, induces acute type of ileitis, in particular distal jejunum and proximal ileum, in rats. ${ }^{27}$ In general, chemically induced colitis models are easy to initiate inflammation and are very useful for the screening of new drugs for human IBD.

\section{Adaptive Cell Transferred Models}

Naïve $\mathrm{CD} 4^{+} \mathrm{T}$ cell population are included in the CD45RB ${ }^{\text {high }}$ fraction, and memory $\mathrm{CD} 4^{+} \mathrm{T}$ cells, which are already primed by specific antigen, are included within $\mathrm{CD}^{2} 5 \mathrm{RB}^{\text {low }}$ fraction. ${ }^{28}$ Powrie et al. ${ }^{29}$ reported that adaptive transfer of $\mathrm{CD} 4^{+}$ CD45RB ${ }^{\text {high }} \mathrm{T}$ cells, which are isolated from spleen of wild-type mice, into scid mice result in subacute colitis approximately 6 to 12 weeks after cell transfer. However, scid mice that received $\mathrm{CD}_{45 \mathrm{RB}}{ }^{\text {high }}$ and $\mathrm{CD} 45 \mathrm{RB}^{\text {low }}$ fractions together do not develop severe colitis since $\mathrm{CD} 45 \mathrm{RB}^{\text {low }}$ fraction includes regulatory $\mathrm{T}$ cells. ${ }^{29,30}$ This model allows to examine some of the earliest immunological factors involved in the induction and/or perpetuation of colitis. ${ }^{31}$ However, CD45RB cell transfer model needs to purify the $\mathrm{CD} 45 \mathrm{RB}^{\text {high }}$ cells by utilizing a cell sorter and the expert intravenous injection skill is required to administer the isolated $\mathrm{CD} 45 \mathrm{RB}^{\text {high }}$ cells to mice.

\section{Congenital (Spontaneous Gene Multination) Models}

$\mathrm{C} 3 \mathrm{H} / \mathrm{HeJBir}$ (C3Bir) mice, which have a missense mutation in the third exon of the Tlr4 (Toll-like receptor 4) gene, spontaneously develop inflammation in cecum and colon. ${ }^{32}$ The inflammation peaks at 3-6 weeks old with resolution by 12 weeks old with an occasional recurrence of colitis after 1 year old. ${ }^{32}$ Interestingly, IL-10-deficient C3Bir mice developed much more severe colitis with severe ulcerative inflammation, epithelial hyperplasia as compared to IL-10 KO mice. ${ }^{33}$

The SAMP1/YitFc mouse strain develops CD-like ileitis around 10 weeks of age with elevated interferon-gamma (IFN $\gamma$ ) and TNF- $\alpha .{ }^{34}$ Global expansion of the stem cells in crypt epithelium, of which accompanied with severity of colitis, can be observed in these mice. ${ }^{35}$ Of note, both IL-13 and IL-5 expression levels are significantly increased in these mice, suggesting the Th2 pathway seems to also contribute during the chronic stage of inflammation. ${ }^{35}$ One of the highest advantages of the SAMP1/YitFc mice model is that it can be utilized as a close CD model, which shows perianal disease with fistula formation in approximately $5 \%$ of mice. However, this spontaneous ileitis takes more long time ( $>30$ weeks of age) to develop transmural inflammation in the terminal ileum with $100 \%$ penetrance. $^{17}$

\section{IBD SUSCEPTIBILITY GENES AND THOSE ANIMAL MODELS}

Since the identification of IBD susceptibility gene NOD2 (nucleotide-binding oligomerization domain-containing protein 2) in 2001, more and more genes of IBD are being identified by GWASs. In humans, more than 350 genes have now been identified. In animal experiments of IBD, it has been reported that more than 74 types of genetically engineered mouse strains spontaneously develop colitis so far. ${ }^{4}$ The IBD susceptibility gene deficient mice models can be utilized to clarify the function and the role of particular genes during the development of intestinal inflammation. However, the phenotype may be different depending on the cell or tissue type in which the IBD susceptibility gene is abrogated.

Nod2 is a CD-specific susceptibility gene and NOD2 recognizes single-stranded RNA of bacteria and viruses, removes foreign substances through the activation of nuclear factor- $\mathrm{\kappa B}$, and is involved in innate immunity. ${ }^{36}$ In addition, about 78 genes such as PTPN22, IL2RA, IL27, TNFSF11, and VAMP3 have been identified as CD-specific susceptibility genes so far. ${ }^{4}$ In UC, there are about 59 UC-specific susceptibility genes including HNF4A (involved in the intestinal epithelial barrier mechanism) and CDH1 (encoding E-cadherin, a cell adhesion molecule). ${ }^{4}$ More than 140 susceptibility genes common to CD and UC have been reported. In particular, the IL23R/ Th17 signaling pathway of IL-23R, IL-22, IL-10R2, STAT3 (signal transducer and activator of transcription 3) and MUC1 (mucin 1) is especially important for the development of colitis. $^{37,38}$

Genetically manipulated IBD animal models including KO and $\mathrm{Tg}$ mice of the above human susceptibility genes are utilized to further prove the direct/indirect association(s) of those genes in IBD. Among them, IL-10RA and/or IL-10RB mutations cause very severe early onset IBD due to unregulated regulatory signals via IL-10. ${ }^{15,16}$ In contrast, Nod2 KO mice as well as Atg16Ll mutant mice do not develop spontaneous colitis or ileitis. ${ }^{38,39}$ Although Atg16Ll mutant mice do not develop spontaneous intestinal inflammation, these mice do cause Paneth cell dysfunction and endotoxin overproduction. $^{40,41}$ These results suggest that a single mutation of Nod2 or Atg16L1 is not sufficient for spontaneous induction of colitis, and the pathogenesis of IBD seems to be more complicated than we initially predicted. ${ }^{42}$ 


\section{PATHOGENIC FACTORS IN ANIMAL MODELS OF IBD}

There are many genetically modified mice that spontaneously develop colitis (Fig. 1). Within those models, T cell receptor $\alpha$ chain (TCR $\alpha$ ) KO mice established by our group in 1993, have been often used as a murine model of UC and useful for identification of many pathogenic factors involved in IBD. ${ }^{3,43,44} \mathrm{Ap}$ proximately $60 \%$ of TCR $\alpha$ KO mice develop Th2-mediated colitis by 6 months of age. ${ }^{3,43}$ However, the severity of colitis and the frequency of onset of colitis in TCR $\alpha$ deficient mice alter depending on strains and animal facilities. ${ }^{3}$ TCR $\alpha$ KO mice have impaired thymic selection (abrogation of negative selection), resulting in the lack of regulatory $\mathrm{T}$ cells and differentiation of $\mathrm{CD} 4^{+} \mathrm{TCR} \alpha \beta^{+} \mathrm{T}$ cells, which develop colitis mediated the production of IL- $4 .{ }^{45-47}$ These TCR $\alpha \beta^{+}$T cells are immunologically functional as shown by cytokine profile and the TCR repertoire pattern. ${ }^{46,47}$ Interestingly, it has been clarified that these pathogenic TCR $\alpha \beta^{+}$T cells are also present in human

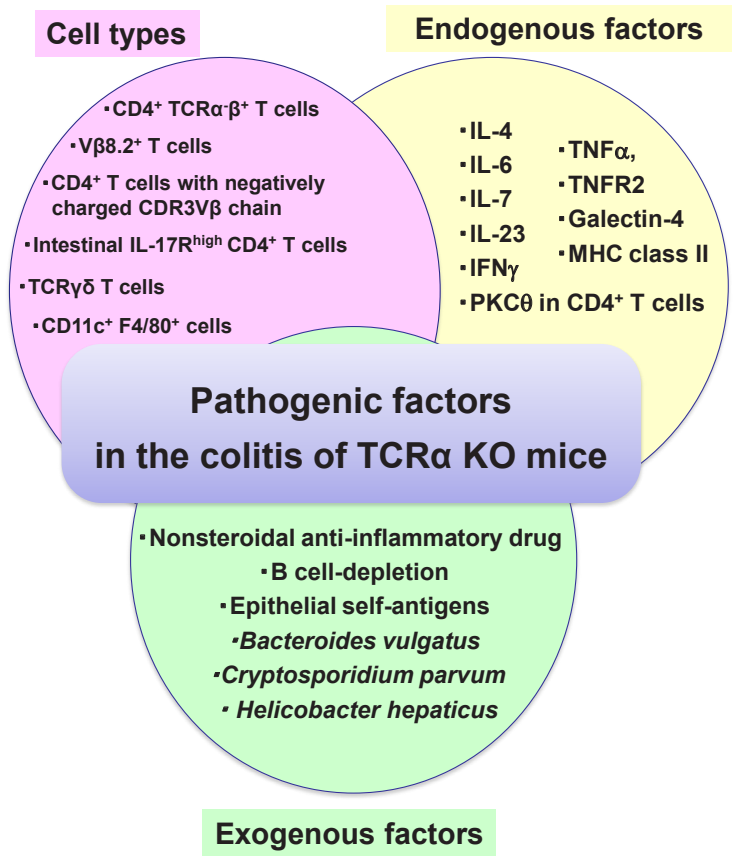

Fig. 2. Major pathogenic factors in T cell receptor alpha chain (TCR $\alpha$ ) knockout (KO) mice with colitis. Several factors are involved in the pathogenesis of colitis in TCR $\alpha$ KO mice., ${ }^{3,10}$ These mice have unique $C D 4^{+} T C R \alpha^{-} \beta^{+} T$ cells, which actively produce IL4. ${ }^{43,47}$ In addition to these characteristic T cells, endogenous as well as exogenous factors are also involved in the pathogenesis of TCR $\alpha$ KO mice. CDR, complementarity determining region; IFN, interferon; IL, interleukin; MHC, major histocompatibility complex; PKC, protein kinase C; TNFR2, TNF receptor 2. with an autoimmune condition. ${ }^{48}$

Under germ-free conditions, the onset of colitis was suppressed in TCR $\alpha$ KO mice. ${ }^{49}$ Moreover, TCR $\alpha$ KO mice spontaneously develop colitis independently of Helicobacter species, whereas TCR $\beta$ KO mice develop Helicobacter species dependently. ${ }^{50,51}$ Furthermore, the permeability of epithelial cells, which is prone to increase in the context of bacterial infection, remains unchanged in TCR $\alpha \mathrm{KO}$ mice. ${ }^{17}$ Interestingly, the development of colitis in TCR $\alpha$ KO mice was not observed in facility under conventional conditions, and regulatory B-1 B cells seem to prevent the development of colitis under non-hygienic conditions. ${ }^{52,53}$

As shown in Fig. 2, several cell types and factors have been

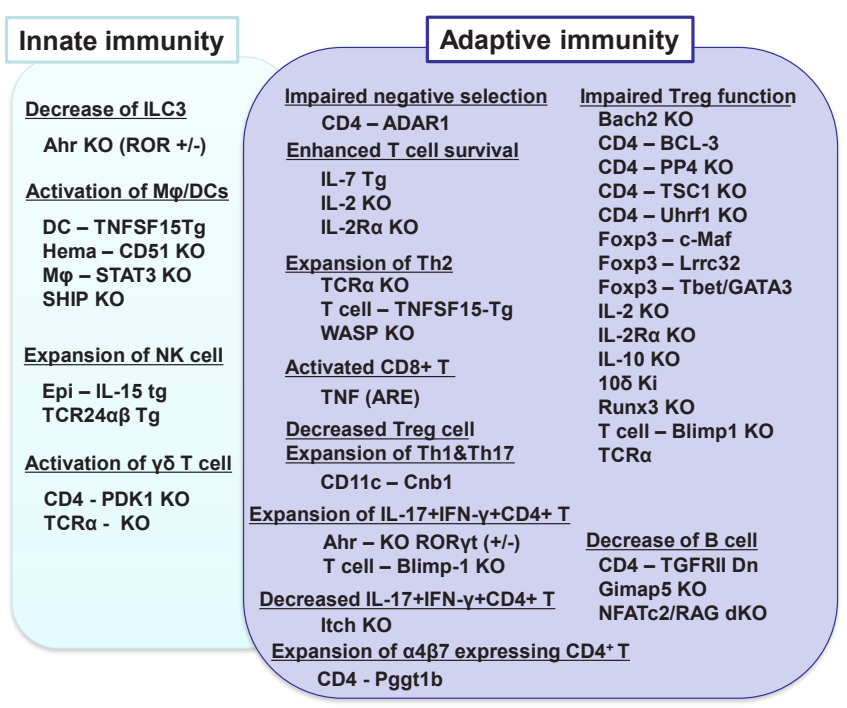

Fig. 3. Major pathogenic pathways of IBD in innate versus adaptive immunity. Genetically manipulated murine models of IBD, which are mainly focused on immunological responses have been shown. Mouse models involved in innate immunity and adaptive immunity are shown in light blue and light purple, respectively. ADAR1, adenosine deaminase acting on RNA 1; Ahr, aryl hydrocarbon receptor; Bach2, BTB domain and CNC homolog 2; Blimp1, B-lymphocyte-induced maturation protein 1; DC, dendritic cell; Dn, dominant-negative; GATA3, GATA binding protein 3; Gimap5, GTPase, IMAP family member 5 ; Itch, itchy E3 ubiquitin protein ligase; Ki, knock-in; KO, knockout; Lrrc32, leucin rich repeat containing 32; NFATc2, nuclear factor of activated T-cells, cytoplasmic 2; PDK1, 3-phosphoinositide-dependent protein kinase 1; PP4, protein phosphatase 4; ROR, RAR-related orphan receptor; Runx3, runt-related transcription factor 3 ; SHIP, SH-2 containing inositol 5 ' polyphosphatase; Tbet, T-box protein 21; TGFRII, transforming growth factor beta receptor type $2 ;$ Treg, regulatory $T$ cell; TNFSF15, TNF superfamily member 15; TSC1, tuberous sclerosis complex 1; Uhrf1, ubiquitin-like, containing PHD and RING finger domains 1; WASP, Wiskott-Aldrich syndrome protein. 


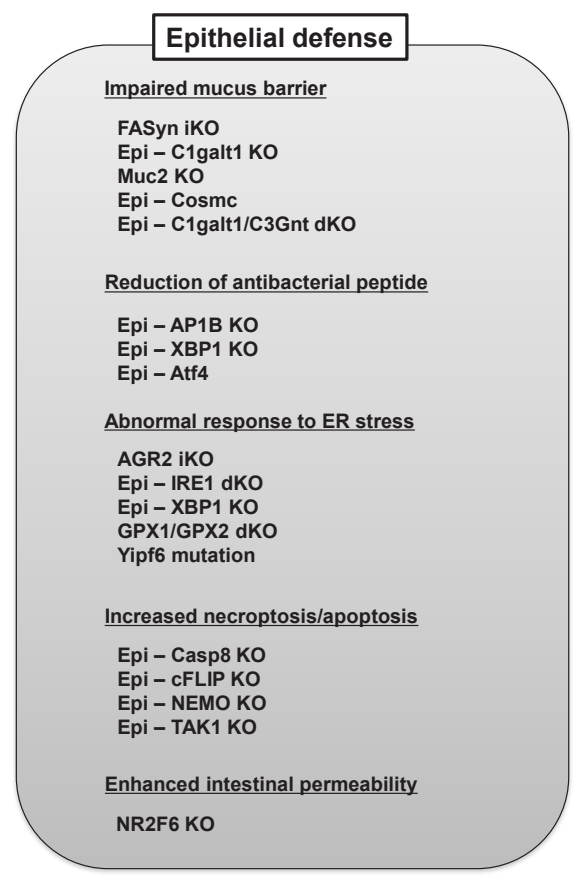

Fig. 4. Major pathogenic pathways of IBD in epithelial defense systems. Genetically manipulated murine models of IBD, which are mainly focused on the deficiency of epithelial defense systems have been shown. AGR2, anterior gradient protein 2 homolog; AP1B, adaptor related protein complex 1 subunit beta 1 ; Atf4, activating transcription factor 4 ; C1galt1, core 1 synthase, glycoprotein- $\mathrm{N}$-acetylgalactosamine 3-beta-galactosyltransferase 1 ; C3 Gnt, core 3 beta 1,3-N-acetylglucosaminyltransferase; Casp8, caspase 8; Epi, epithelial cells; FASyn, fatty acid synthase; GPX, glutathione peroxidase; IRE1, inositol-requiring enzyme 1; Muc2, mucin 2; NEMO, NF-kappa-B essential modulator; NR2F6, nuclear receptor subfamily 2 , group $F$, member 6 ; TAK 1 , transforming growth factor-beta activated kinase $1 ; \mathrm{XBP} 1, X$-box binding protein 1; Yipf6, Yip1 domain family member 6 .

identified that play pathogenic roles in the colitis of TCR $\alpha \mathrm{KO}$ mice. Another interesting feature of TCR $\alpha \mathrm{KO}$ mice is the important role of regulatory B cells, so called Breg, in the colitis. ${ }^{54,55}$ In B cell deficient TCR $\alpha$ KO mice, colitis much more worsened as compared to TCR $\alpha$ KO mice, suggesting that B cells play a protective role in colitis. ${ }^{54-56}$ Although B cells were previously thought not to be the main source of cytokines, the B cells in colitis TCR $\alpha$ KO mice with colitis produce large amounts of IL-10 and IL-12 (p70), suggesting that they contribute to improvement of the disease. ${ }^{56,57}$ These findings suggest the existence of regulatory B cells as well as pathogenic B cells in UC patients. Indeed, results of randomized placebocontrolled trials have been shown that B cell depletion therapy by rituximab (humanized anti-CD20 monoclonal antibody
$[\mathrm{mAb}])$ is ineffective in inducing remission of moderately active UC. ${ }^{58}$ Furthermore, a case report shows that B cell depletion with the anti-CD20 mAb correlates with IL-10 production and exacerbates UC. ${ }^{59}$ In the other 3 case reports, the development of UC patients progressed after B cell depletion therapy and was induced complication of other autoimmune diseases. ${ }^{60}$

There are lots of genetically engineered mice, which develop spontaneous colitis (Fig. 1). Pathogenic factors in IBD including dysregulated immune responses, impaired epithelial barrier function, the cytokines, and microbiota could be identified by utilizing these mouse models of IBD.

Forty kinds of immune cell-specific KO mice are spontaneously induced the intestinal inflammation, which dues to the reasons such as dysregulated innate and adaptive immunity responses (Fig. 3). In addition, 18 kinds of intestinal epithelial cell-specific KO mice develop spontaneous colitis, which are caused by impaired mucosal barriers, unregulated necroptosis/apoptosis, reduction of antibacterial peptide and/or abnormal response to endoplasmic reticulum stress (Fig. 4).

As shown in Fig. 1 as well as some of the references, IL-10 is one of the most important anti-inflammatories and regulatory cytokines, which is produced by many kinds of cells including macrophages, T cells and B cells. ${ }^{15,16}$ Kühn et al. ${ }^{1}$ established IL-10 KO mice, which spontaneously develop chronic enterocolitis after 3 months of age with marked regenerative crypt hyperplasia in the colon. Enteric flora plays the key role during the development of colitis in IL-10 KO mice: The inflammation is much milder (restricted in the colon but not in the small intestine) under specific pathogen-free conditions as compared to conventional conditions, and the colitis has been shown to be dependent on Helicobacter-species infection. ${ }^{61}$ Furthermore, colitis in IL-10 KO mice is abolished under germ-free condition suggesting resident enteric bacteria are required for spontaneous colitis and immune system activation in IL-10 KO mice. ${ }^{62}$ Interestingly, anaerobic bacteria and aerobic bacteria play different role in this colitis: Metronidazole is effective for the treatment of colitis but not typhlitis (inflammation in the cecum), while Ciprofloxacin is beneficial for the treatment of typhlitis but not colitis. ${ }^{63}$ Although the colitis in IL-10 KO mice are often referred as Thl-type, IFN $\gamma$ plays a protective role in this colitis since IFN $\gamma \times$ IL-10 DKO mice develop more severe colitis as compared to IL-10 KO mice. ${ }^{64} \mathrm{In}$ fact, recent GWAS have identified $I l 10$ as susceptibility gene for both UC and CD, so we should not use IL-10 KO mice as a simple CDlike model. ${ }^{17}$ 


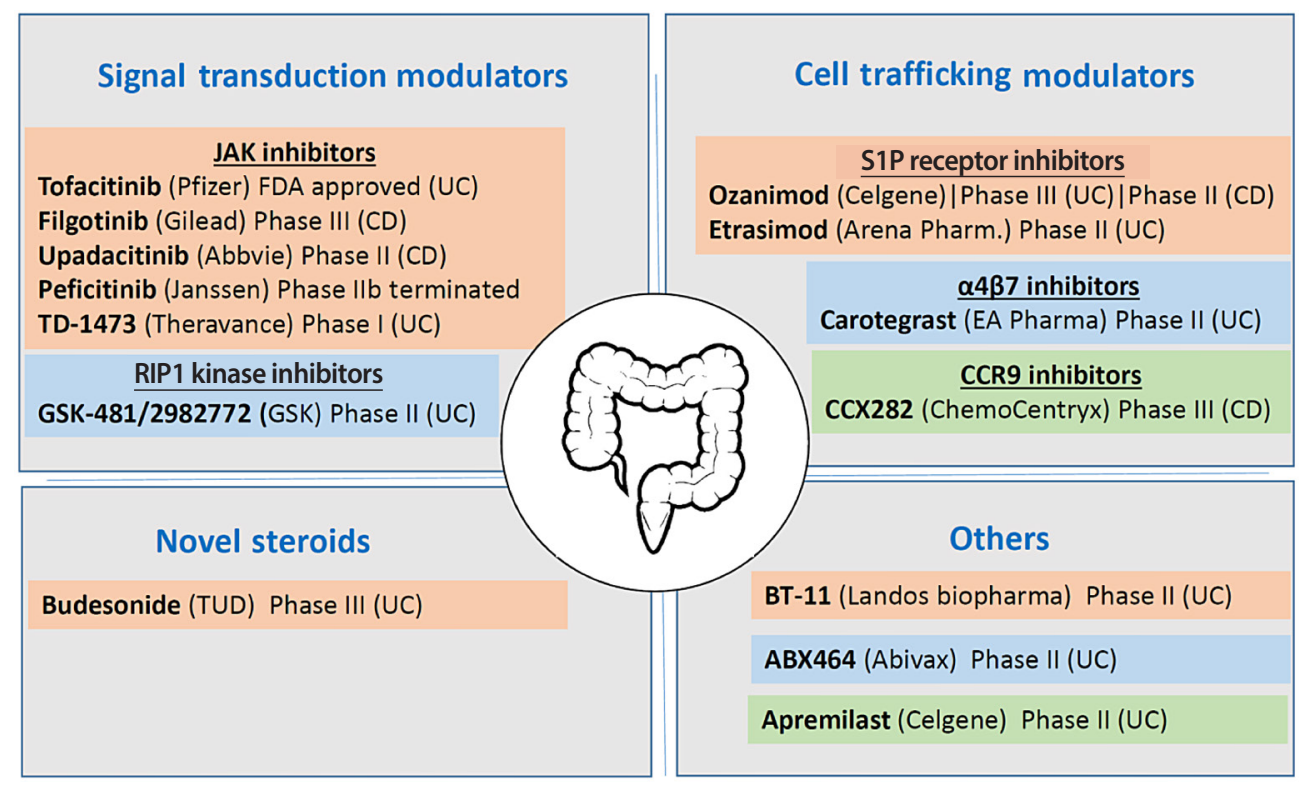

Fig. 5. Key small molecule compounds. A summary of the key small molecule compounds under development that had undergone evaluation in experimental colitis model and progressed onto successful clinical testing. JAK, Janus kinase; FDA, Food and Drug Administration; S1P, sphingosine-1 phosphate; RIP1, receptor-interacting protein 1; CCR9, chemokine receptor 9.

\section{ROLE OF ANIMAL MODELS IN IBD TREATMENT}

Currently, several modalities of treatments could be considered for the management of IBD. These include (1) small molecules (e.g., corticosteroids and mesalazine), (2) biologics (e.g., anti-TNF- $\alpha$ ), (3) emerging therapies (e.g., stem cell therapy and fecal microbiota transplantation [FMT]), as well as (4) alternative therapies (e.g., traditional Chinese medicine). Animal models could provide a platform for inference of efficacy and safety for the development of some of these treatments and will continue to play a supporting role in facilitating the discovery of new drugs and treatment for IBD.

Interestingly, in one of the highly cited studies on translational of research evidence from animals to human showed that only $10 \%$ of these interventions from animal studies were subsequently developed into something that could be fit for patient use. ${ }^{65}$ In the case of biologics, there are more than 60 potential new targets involving more than 600 phase I-III clinical trials, but only a few, including anti-TNF- $\alpha$ agents, natalizumab, ustekinumab and vedolizumab, made it to the clinical application eventually. This is likely due in part to poor methodology and failure of the models to accurately mimic the human disease condition and suggested improvements to increase translational success rates have been previously proposed. ${ }^{66}$

Certainly, there are limitations inferring observations from animal models. Particularly, human IBD is polygenic and mul- tifactorial in nature, in contrast to experimental IBD animal model that usually involves disruption or overexpression of single genes and thus limiting systemic pathways. Another limitation of extrapolating animal models into human safety and efficacy is the qualitative and quantitative measurement of outcomes. Human clinical trials for IBD measures disease activities through various indexes that quantify symptoms related to active disease, including the CDAI and the Mayo Clinic score for UC. In contrast, efficacies of interventions in animal models are usually assessed through histopathology score of colonic inflammation and clinical score. These parameters might not be sufficient to make inference to clinical remission in heterogeneous groups of patients. In addition, other pharmacological considerations, including bioavailability, time and route of administration, as well as dosing are also important factors to affect the difference between experimental colitis data with actual human context.

The subsection below provides a deeper dive into how animal contributes towards the development of the 2 main modalities of treatment, small molecules, and biologics for IBD.

\section{Small Molecules}

Small molecules medications remain the most common used first line of treatment for IBD. These include 5-aminosalicylates and immunosuppressive agents such as methotrexate and thiopurines, as well as corticosteroids which can be effec- 
tive in inducing remission but negative side effects preclude their long-term use. However, many times the response rates vary and disease recurrence are common and therefore there remains a significant unmet medical need in IBD. The goal for new therapies is to induce and maintain clinical remission in a greater proportion of patients than is currently achievable with standard-of-care agents. Fig. 5 summarizes some of the key small molecule compounds under development that had undergone evaluation in experimental colitis model and progressed onto successful clinical testing.

\section{Signal Transduction Modulators}

Signal transduction modulators are one of the major groups of targets for the development of small molecule therapy for IBD. One class that had been widely focused is the Janus kinase (JAK)/STAT pathway, which has been implicated in the etiology of many other diseases, in addition to IBD, and a number of selective compounds have entered clinical development (Fig. 5). For example, Tofacitinib is a nonselective JAK inhibitor that had been previously approved by Food and Drug Administration for rheumatoid arthritis and psoriatic arthritis. Tofacitinib potently inhibits JAK1, JAK2, and JAK3 and, to a lesser extent, TYK2 in biochemical assay (IC50 $=3.2,4.1,1.6$, and $34 \mathrm{nM}$ respectively). It had been shown in rat oxazolone colitis model that tofacitinib exhibit anti-inflammatory effects in vivo. ${ }^{67}$ The effect of tofacitinib had also been shown to exhibit similar efficacy, when dosed orally or intra-cecally, in oxazolone-induced colitis in mice, but noting that intra-cecal provides colonic target engagement which do not impact splenic natural killer (NK) cell counts. ${ }^{68}$ Consistent with the notion that oxazoloneinduced colitis represents features of human UC condition, tofacitinib had been found effective for UC patients and was approved recently in May 2019 for use in moderately to severely active UC in clinical settings. Conversely, tofacitinib did not show significant improvements in remission rates, in comparison with placebo, in a phase II clinical trial for CD. ${ }^{69}$ Another major JAK inhibitor that is currently under clinical phase III trial is Filgotinib, which has a human whole blood EC50 of $629 \mathrm{nM}$ displaying a 30-fold cellular selectively for JAK1 over JAK2.$^{70,71}$ Filgotinib efficacious effect was previously evaluated in DSS-induced colitis model and showed good in vitro ADME (absorption, distribution, metabolism, excretion) properties and high oral bioavailability in animals. In addition, upadacitinib is also another potent JAK1 inhibitor that effectively inhibits production of pro-inflammatory cytokines IL-6, oncostatin M, IL-2 and IFN $\gamma$ in a variety of cellular assay. ${ }^{72}$ The compound is currently under clinical trial phase II evaluation.

\section{Cell Trafficking Modulators}

Cell trafficking modulators is the other major category that is being explored for the development of small molecule treatment for IBD. For example, sphingosine-1 phosphate (S1P) is a key regulator of lymphocyte migration from lymph nodes, and blocking this pathway has been considered as a potential approach to control aberrant leukocyte migration into the mucosa in $\mathrm{IBD}^{73}$ In this regard, ozanimod was developed as a potent agonist of S1P1 $($ EC50 $=0.16 \mathrm{nM})$ and S1P5 $($ EC50 = $4.3 \mathrm{nM})$ and binds directly to the S1P receptor. Administration of ozanimod into mouse T cell adoptive transfer model of colitis protects the animals from body weight loss and reduced inflammation. ${ }^{74}$ In addition, ozanimod administration at a $0.6 \mathrm{mg} / \mathrm{kg}$ in TNBS-induced colitis model in rats also protected animals from weight lost, reduce the number of circulating lymphocytes by $51 \%$, resulting in significant improvements in disease scores. ${ }^{75}$ With such promising results, the compound progressed into both UC and CD clinical trials, in which they are currently under phase III and phase II evaluation respectively. In addition, etrasimod is another compound designed to target S1P1, S1P4, and S1P5 receptor with EC50 values of 6.1, 147, and $24.4 \mathrm{nM}$, respectively. It was shown in scid mice receiving $\mathrm{CD}^{+} \mathrm{CD}^{2} 5 \mathrm{RB}^{\text {high }} \mathrm{T}$ cells that administration of $3 \mathrm{mg} / \mathrm{kg}$ dose of etrasimod provided significant protection towards weight loss in the colitis-induced animals. The compound then progressed onto clinical trials (currently at phase II). Moderate-to-severe UC patients were given $2 \mathrm{mg}$ dose for 12 weeks, and $43 \%$ patients showed endoscopic improvements as compared to $16.3 \%$ in the placebo group. ${ }^{76}$ The encouraging result had led to propose extension of the clinical evaluation to $\mathrm{CD}$.

$\alpha 4 \beta 7$ integrin is expressed on circulating T cells and mediates cell trafficking throughout the body, whereas its natural ligand is the mucosal vascular addressin cell adhesion molecule 1 (MadCAM) that is expressed predominately on the mucosal endothelium of the GI tract. Binding of MadCAM to $\alpha 4 \beta 7$-expressing T cells would render cell capture, adhesion and extravasation, thus leading to infiltration of pro-inflammatory $\mathrm{T}$ cells in the inflamed gut of IBD patients. Compounds such as carotegrast $(\mathrm{EC} 50=1.4 \mathrm{nM})$ had been shown to potently inhibit the binding of $\alpha 4 \beta 7$ expressing cells to MadCAM. Oral dosing of methyl ester prodrug of carotegrast in mice inhibited leukocytes homing to Peyer's patches with an EC50 of $180 \mathrm{nM}$. In IL-10 deficient CD4 ${ }^{+} \mathrm{T}$ cell transfer model of colitis, administration of carotegrast reduced IL-17, IFN $\gamma$, and TNF- $\alpha$ 
Table 1. Responses in Experimental Colitis Model to Biologics

\begin{tabular}{|c|c|c|c|}
\hline Target & Type & Effective model & $\begin{array}{l}\text { Ineffective } \\
\text { model }\end{array}$ \\
\hline \multirow[t]{8}{*}{ TNF- $\alpha$} & Prevention & Chronic DSS & Acute DSS \\
\hline & & $\operatorname{Tg} \varepsilon 26$ & $\mathrm{IL}-10^{-/-}$ \\
\hline & & $\begin{array}{l}\text { IL1OR2 }{ }^{-1-} \text { X TGF } \beta \text { RII DN } \\
\text { TNF- } \alpha\end{array}$ & \\
\hline & & CD45RB high & \\
\hline & Treatment & Chronic DSS & \\
\hline & & TNBS & \\
\hline & & SAMP1/YitFc & \\
\hline & & TRUC & \\
\hline \multirow[t]{9}{*}{ IFN $\gamma$} & Prevention & Chronic DSS & TNBS \\
\hline & & CD45RB $B^{\text {high }}$ & \\
\hline & & SAMP1/YitFc & \\
\hline & & $\mid \mathrm{L}-10^{-1-}$ & \\
\hline & & $\mathrm{Hh} / \mathrm{IL}-10^{-1-}$ & \\
\hline & & dnKO colitis & \\
\hline & & Anti-CD40 & \\
\hline & Treatment & - & $\mid \mathrm{L}-10^{-/-}$ \\
\hline & & & $\mathrm{Hh} / \mathrm{IL}-10^{-/-}$ \\
\hline \multirow[t]{2}{*}{ IL-13 } & Prevention & Oxazolone & \\
\hline & Treatment & - & \\
\hline \multirow[t]{2}{*}{ |L-17 } & Prevention & - & DSS \\
\hline & Treatment & - & \\
\hline \multirow[t]{6}{*}{ IL-12/23 (p40) } & Prevention & TNBS & \\
\hline & & $\mathrm{IL}-10^{-1-}$ & \\
\hline & & $\operatorname{Tg} \varepsilon 26$ & \\
\hline & & $\mathrm{CD} 40 \mathrm{mAb}$ & \\
\hline & Treatment & $\mathrm{IL}-10^{-/-}$ & \\
\hline & & TNBS & \\
\hline \multirow[t]{3}{*}{ IL-23 (p19) } & Prevention & $H h \rightarrow R A G^{--}$ & \\
\hline & & $\mathrm{CD} 40 \mathrm{mAb}$ & \\
\hline & Treatment & - & \\
\hline \multirow[t]{6}{*}{ IL-6R } & Prevention & CD45RB $B^{\text {high }}$ & \\
\hline & & SAMP1/Yit & \\
\hline & Treatment & TNBS & \\
\hline & & $\mid \mathrm{LL}-10^{-1-}$ & \\
\hline & & CD45RB high & \\
\hline & & SAMP1/Yit & \\
\hline \multirow[t]{3}{*}{ IL-18 } & Prevention & DSS & \\
\hline & & TNBS & \\
\hline & Treatment & TNBS & \\
\hline
\end{tabular}

(Continued to the next)
Table 1. Continued

\begin{tabular}{|c|c|c|c|}
\hline Target & Type & Effective model & $\begin{array}{c}\text { Ineffective } \\
\text { model }\end{array}$ \\
\hline \multirow{5}{*}{$\begin{array}{l}\text { MAdCAM-1/ } \\
\alpha 4 \beta 7\end{array}$} & Prevention & DSS & \\
\hline & Treatment & DSS & SAMP1/YitFc \\
\hline & & Chronic DSS & DSS \\
\hline & & CD45RB ${ }^{\text {high }}$ & \\
\hline & & SAMP1/YitFc & \\
\hline \multirow[t]{4}{*}{ ICAM- $1 / \alpha 4 \beta 1$} & Prevention & DSS & \\
\hline & & TNBS & \\
\hline & Treatment & DSS & SAMP1/Yit \\
\hline & & & DSS \\
\hline \multirow[t]{3}{*}{ VCAM-1 } & Prevention & TNBS & \\
\hline & Treatment & $\begin{array}{l}\text { Cotton-top tamarin } \\
\text { colitis }\end{array}$ & SAMP1/Yit \\
\hline & & DSS & \\
\hline
\end{tabular}

DSS, dextran sodium sulfate; IL, interleukin; TNBS, 2,4,6-trinitrobenzene sulfonic acid; TRUC, T-bet-/- RAG2-I- UC; IFN $\gamma$, interferon $\gamma$; dnKO, dominant-negative knockout; mAb, monoclonal antibody; IL-6R, IL-6 receptor; MAdCAM, mucosal vascular addressin cell adhesion molecule; ICAM, intracellular adhesion molecule; VCAM, vascular cell adhesion molecule.

levels and significantly reduced the amount of $\mathrm{T}$ cells migration in the lamina propria. ${ }^{77}$ Carotegrast has now been evaluated under a phase II study for UC and current result shows clinical remission of $23.5 \%$ versus 3.9 (placebo) at dose of 960 $\mathrm{mg}^{78}$

Another class of compound under development for IBD therapy that aims to mediate cell trafficking is the chemokine receptor 9. These receptors are G-protein-coupled receptor superfamily cell surfaced receptors expressed on circulating lymphocytes, and its natural ligand (CCL25) is expressed on the intestinal lumen epithelial cells. Ligand-receptor engagement results in the induction of chemotaxis of lymphocytes to the intestines. Compounds such as CCX282 had been developed to break this interaction and inhibit chemotaxis of Baf-3 cells, resulting in protection against inflammation in the $\mathrm{TNF}^{\triangle \mathrm{ARE}}$ mice model ${ }^{79}$ Currently, CCX282 at $250 \mathrm{mg}$ had shown promising results in a phase II study for CD, but showed less efficacy in subsequent phase III trials. ${ }^{80}$

\section{Biologics}

Biological therapies have an increasing share in the modern therapeutics of various diseases including IBD. Current biological treatments generally involve either (1) blockage of proinflammatory cytokines produced by effector T cells, (2) 
blockage of pro-inflammatory cytokines produced by antigen presenting cells (APCs), (3) inhibition of pathogenic T cell responses via administration of anti-inflammatory cytokines, (4) targeting T cell activation, proliferation, and apoptosis, (5) enhancement of the innate immune system, and (6) inhibition of leukocyte migration to mucosal sites.

In Table 1, we have summarized some of these biologics and its responses in IBD animal models. Anti-TNF- $\alpha$ antibody is currently the most widely applied biologics for IBD, but interestingly this form of treatment did not exhibit encouraging results in animal models prior to the first randomized controlled trials (RCT). Studies in CD45RB ${ }^{\text {high }}$ cell transfer model of colitis prior to RCT in humans showed only partial protection by anti-TNF- $\alpha$ antibody treatment with no long-term immunomodulatory effects compared with IFN $\gamma$ neutralization methods. ${ }^{81}$ TNF- $\alpha$ neutralization in an acute DSS-induced colitis model also exhibits no effects or even aggravated inflammation and delayed recovery. ${ }^{82}$ In addition, anti-TNF- $\alpha$ antibody also failed to prevent or treat the disease in IL-10 KO mice. ${ }^{83}$ However, subsequent evaluation of effects of antiTNF- $\alpha$ therapy using other experimental colitis models confirmed its efficacy, including chronic DSS-induced colitis model (Table 1). This also shows that variability of phenotypic effect exists, and thus selection of the right animal model is crucial to demonstrate effectiveness of treatment.

In the case of targeting IFN $\gamma$, the aim is to reduce this proinflammatory product of activated T cells, NK cells and macrophages that had been shown to be elevated in human CD inflamed mucosa. Fontolizumab is a mAb against IFN $\gamma$ that is currently under phase II clinical testing. Previously studies and data from experimental colitis model had demonstrated protective effect using anti-IFN $\gamma$, as seen in different model such as SAMP1/YitFc and IL-10 KO murine models. ${ }^{35,81,84}$ However, in contrast to its protective effect, the ameliorative effect of anti-IFN $\gamma$ of established colitis had not been well address. IL-10 KO colitis model showed no improvements when treated with anti-IFN $\gamma$ antibody. These results inferred from animal models appeared to be in sync with the fact that fontolizumab did not reach the clinical response primary efficacy end point at day 29 .

Another popular target is IL-13, given its pathogenic role in affecting epithelial tight junction, apoptosis and colonic epithelial cell restitution. IL-13 is mainly produced by NK T cells and $\mathrm{CD}^{+}{ }^{+} \mathrm{T}$ cells, and eliminating its effect either through IL13 neutralizing, depletion of NK T cells, or IL-13 deficiency in $\mathrm{CD}^{+} \mathrm{T}$ cells all protected mice from colitis. ${ }^{85,86}$ In contrast to its protective effect, there has been limited positive data on ameliorating established disease. Currently, anrukinzumab and tralokinumab are under phase II trials assessing pharmacokinetics and safety in UC patients, and QAX576 (i.e., an IL13 antagonist) is also under phase II clinical evaluation.

As mentioned above, blockage of pro-inflammatory cytokines produced by APCs is another approach towards designing IBD therapies. While mechanistically, experimental colitis model, including IL-10 KO mice model, provided evidence that the initiation and maintenance of Th1- and Th17-polarized $\mathrm{T}$ cell responses during chronic intestinal inflammation depends on the production of IL-12 (p35/p40) and IL-23 (p19/p40) from resident APCs. However, effects of treatment in animal models targeting anti-p40 to ameliorate established colitis are lacking. Most of the animal studies aiming at blocking APC-produced pro-inflammatory cytokines focuses on IL12 and IL-23 through either p19, p40, and STAT-4 genetic deficiency. Antibodies against p40 (the common subunit of IL-12 and IL-23) include ustekinumab that had been shown to be more effective in both remission induction and maintenance in both CD and UC than placebo. Another antibody against p40 that was evaluated recently is briakinumab. However, studies have shown that briakinumab fail to demonstrate desired efficacy in CD and thus further studies on this asset are unlikely. ${ }^{87}$ In addition, there are also several P19 mAbs currently undergoing clinical evaluation includes; brazikumab (MEDI2070), risankizumab (BI 6555066), guselkumab, mirikizumab (LY3074828), and tildrakizumab (MK 3222). ${ }^{88}$

Another key cytokine central to IBD is IL-6 that is involved in enhancing survival and resistance to apoptosis of lamina propria of T cells. Neutralizing antibodies against the IL-6 receptor (IL-6R) in experimental colitis models, including TNBS, IL-10 KO had been shown to prevent disease development and also to ameliorate established colitis. ${ }^{89,90}$ It was suggested that the mechanism was via induction of $\mathrm{T}$ cell apoptosis through STAT-3 signaling pathway preventing the upregulation of anti-apoptotic gene expressions such as Bcl-2 and Bclxl. Current biologics targeting IL-6 associated effects include PF 04236931 (antibody against IL-6), as well as tocilizumab (antibody against IL-6R).

Similar to small compounds that prevent leukocyte migration to mucosal sites by targeting $\alpha \mathrm{E} \beta 7$ and MAdCAM- 1 , several antibodies had also been developed to achieve such effect. ${ }^{91}$ For example, etrolizumab, which acts on $\beta 7$-integrin, is currently undergoing clinical trials. It was shown that etrolizumab decreased the accumulation of $\mathrm{CD}^{+}$and $\mathrm{CD} 4^{+} \mathrm{Th} 9$ 
cells in the mice intestines more strongly than vedolizumab. ${ }^{92}$ PF-00547569, which targets MAdCAM-1, is also currently undergoing clinical evaluation.

It is projected that many therapies will become available in the coming years if supported by the results of current clinical trials. This will provide IBD patients with a wide array of options and allow physicians to choose the best therapies for each individual patient. Experimental models of colitis continue to provide a powerful tool to indicate effectiveness and safety of these novel therapies, and the ability to infer mechanisms of action.

\section{Microbiota}

Gut microbiota dysbiosis represents another key factor involved in the pathogenesis of IBD and is now an attractive target for therapeutic development. Many reviews had described the use of prebiotics and probiotics to ameliorate disease using experimental models to restore the normal composition of altered microbial flora. ${ }^{93}$ A more nascent approach is the use of synbiotics, which is a combination of prebiotics and probiotics, to achieve greater treatment efficacy. In addition, FMT is another option to achieve normobiosis restoration. Recent studies on both acute and chronic experimental colitis showed that the therapeutic effects of FMT are linked to functional modulation of the mucosal immune system and of the gut microbiota composition. ${ }^{94,95}$ Specifically, expression of pro-inflammatory genes, antimicrobial peptides, and mucins were observed to decrease in animals receiving the treatment.

While experimental models provide a good platform to explore and develop novel therapeutics targeting the microbiota, these organisms colonize not just the intestine but also many other parts of the body. They are also affected by many other factors including food, bedding, caging, and temperature. Therefore, it is important to keep in mind the proper microbiota standardization when conducting such studies. McCoy et al. $^{96}$ recently described a protocol that aims to reduce variability and improve experimental reproducibility.

\section{FUTURE OUTLOOK FOR THE ROLES AND USE OF ANIMAL MODELS TO STUDY IBD}

\section{Humanized Mouse Model}

While conventional approach towards leveraging the advantages of animal model to gain insights towards both the pathogenesis of IBD through chemical induction and/or genetic manipulation of intestinal inflammation, as well as using it for preclinical studies for drug discovery and development, there had been trends towards utilizing humanize mice to speed up these efforts. ${ }^{97}$ The aim is to mimicry the human disease physiopathology, particularly through the expression of human cytokines or immune cells, and improves bench-to-bedside transition for promising therapeutics. Humanized mouse model also may provide alternative solutions to current methods of adoptive transfer of xenogeneic (human) hemato-lymphoid cells (e.g., hematopoietic stem cells or peripheral blood mononuclear cells) into healthy wild-type mice, which on many occasions results in rapid rejection of these cells and, depending upon the type of cells injected, may result in lethal xenogeneic graft versus host disease.

Advances in this regard of using humanized mice to study IBD was demonstrated by Goettel et al., ${ }^{98}$ on how such tools allow the direct testing of therapeutics on human immune cells which are engrafted into immunodeficient mice. The use of explants or lamina propria mononuclear cells isolated directly from human IBD patient intestinal tissue enable investigators to test therapeutic hypotheses directly on human cells and/or tissue. More recently, Goettel et al. ${ }^{99}$ from the Snapper laboratory also showed how low-dose IL-2 can ameliorates colitis in a preclinical humanized mouse model. Current commercial humanized mouse suitable for IBD studies includes the CIEA NOG mouse ${ }^{\circledR}$ that is engrafted with human CD34 ${ }^{+}$ hematopoietic stem cells.

\section{Artificial Intelligence}

In the new era of leveraging the power of data (e.g., publications, clinical data, high throughput data, large scale genomic data etc.), artificial intelligence (AI) and machine learning (ML) technologies had advanced and matured to analyze these large datasets. This results in increasing application of AI/ML towards both the understanding of disease pathogenesis, as well as for drug discovery and development. These might render that traditional use of expensive animal models may be subsequently replaced by these alternatives in silico method to provide inference and insights on biological research with equivalent or even better outcomes.

Similarly, these AI technologies can also be used in conjunction with animal models, (e.g., pattern recognition of animals in response to perturbation), to complement and provide greater insights and accelerate research. For example, Kozlowski et al., ${ }^{100}$ developed an entirely automated method to score DSS-induced colitis in mice by digital image analysis of pathology slides, allowing less dependence on professional 
pathologist and accurate and unbiased scoring.

Indeed, AI technologies could be used to accelerate IBD research from fundamental studies including analysis of realworld data, to drug discovery and development, and in the clinic. The Nutritional Immunology and Molecular Medicine Laboratory, had created synthetic patient populations of CD and UC patients with properties of actual patient cohorts, and had built personalized predictive models of drug combinations and unravel complex relationships between diet, gut microbiome, immune system, and genetic lineup to determine the comparative treatment response in silico before testing in patients. Another example of applications of AI technologies for IBD was described by Romagnoni et al., ${ }^{101}$ where they took the ImmunoChip dataset containing 18,227 CD patients and 34,050 healthy controls enrolled and genotyped by the International Inflammatory Bowel Disease Genetics Consortium to re-analyzed via a set of ML methods (i.e., penalized logistic regression, gradient boosted trees, and artificial neural networks) and managed to detected nearly all the genetic variants previously identified by GWAS among the best predictors, plus additional predictors with lower effects. Overall, such approach may provide a more superior alternative method to traditional experimental colitis method of understanding the disease by allowing analysis of complex systems through crunching of big data.

\section{Organoid Model}

Increasingly sophisticated tissue organoids can model many aspects of diseases, including IBD, which may provide an alternative method to experimental animal models. Such method not only is more cost-effective, mimics the human body's organ structure, and also contains element of precision medicine. Use of organoid might also be beneficial in countries with strong regulations against animal testing. In addition, organoid models can also help address rare forms of IBD, especially those with very early onset in early childhood, are caused by monogenetic aberrations, for example, in IL-10, IL-10R, X-linked Inhibitor of apoptosis protein (XIAP), neutrophil cytosolic factor 2 (NCF2), or tetratricopeptide repeat domain 7 (TTC7). ${ }^{102}$

Several groups had demonstrated to ability to establish intestinal organoid system that can be used to understand disease pathogenesis. Specifically, Shin and $\mathrm{Kim}^{103}$ led a study in 2018 to use his "gut-inflammation-on-a-chip" technology to confirm that intestinal barrier disruption is the upstream initiator of gut inflammation and made inference for IBD. Xu et al. ${ }^{104}$ had also shown that transcriptional signature of epithelial organoid cultures generated from UC patients and non-IBD controls had differentially gene expression associated with epithelial secretory and antimicrobial defense to support the power of organoid system to study epithelial barrier function. In a separate study, Sarvestani et al., ${ }^{105}$ also created patient-derived primary-organoid cultures from UC and non-IBD colonic epithelium, phenotyped them histologically and used nextgeneration sequencing approaches to profile whole transcriptomes and epigenomes of organoids. They concluded that these primary colonic organoid cultures from UC and nonIBD patients can be established that faithfully represent diseased or normal colonic states.

However, some of the major drawbacks of using intestinal enteroid/organoid cultures are the high cost involved. Specifically, a significant amount of expensive Matrigel, which is derived from natural polymers secreted by mouse sarcoma cells, is required to propagate intestinal enteroids/organoids. A myriad of growth factors required in the culture medium also adds on to the cost involved. In addition, both Matrigel and growth factors from conditioned media contain varying amounts of xenogeneic and undefined components, along with the potential risk of pathogen/immunogen transmission and batch-to-batch variability. ${ }^{106}$

\section{CONCLUSIONS}

Utilizing animal models have highly provided important insights into the pathogenesis of IBD although only limited percentage of clinical interventions from animal studies were subsequently developed into something that could be fit for patient use. However, major pathogenic factors as well as inflammatory modulators are unrevealed based on the genetically engineered mouse IBD models. Alteration of multiple factors including innate immunity, adaptive immunity and epithelial defense play key roles during the development of IBD. In particular, animal models that incorporate variants of human IBD susceptibility genes have become indispensable roles to study these genes in chronic intestinal inflammation mechanistically and therapeutically. It is apparent that no single model is perfect, and therefore we need to utilize ideal/appropriate animal models to define safety and efficacy of designed novel therapeutic strategies for IBD as shown in this review article.

\section{FINANCIAL SUPPORT}

This work was partly supported by grants from the Ishibashi 
Foundation for the Promotion of Science, Japan Society for the Women Health Science, Fukuoka Clinical Medical Research Award, and Japan Society for the Promotion of Science (18K07987) to Mizoguchi E.

\section{CONFLICT OF INTEREST}

No potential conflict of interest relevant to this article was reported.

\section{AUTHOR CONTRIBUTION}

Conceptualization: Mizoguchi E. Writing-original draft: Mizoguchi E, Low D, Okada T, Ezaki Y. Writing-review and editing: Mizoguchi E, Low D, Okada T. Approval of final manuscript: all authors.

\section{ORCID}

Mizoguchi E

Low D

Ezaki Y

Okada T https://orcid.org/0000-0002-4019-0617 https://orcid.org/0000-0001-9721-1856 https://orcid.org/0000-0001-7210-4480 https://orcid.org/0000-0001-7781-2486

\section{REFERENCES}

1. Kühn R, Löhler J, Rennick D, Rajewsky K, Müller W. Interleukin-10-deficient mice develop chronic enterocolitis. Cell 1993; 75:263-274.

2. Sadlack B, Merz H, Schorle H, Schimpl A, Feller AC, Horak I. Ulcerative colitis-like disease in mice with a disrupted interleukin-2 gene. Cell 1993;75:253-261.

3. Mombaerts P, Mizoguchi E, Grusby MJ, Glimcher LH, Bhan AK, Tonegawa S. Spontaneous development of inflammatory bowel disease in T cell receptor mutant mice. Cell 1993;75: 274-282.

4. Mizoguchi A, Takeuchi T, Himuro H, Okada T, Mizoguchi E. Genetically engineered mouse models for studying inflammatory bowel disease. J Pathol 2016;238:205-219.

5. Low D, Nguyen DD, Mizoguchi E. Animal models of ulcerative colitis and their application in drug research. Drug Des Devel Ther 2013;7:1341-1357.

6. Neurath MF. Targeting immune cell circuits and trafficking in inflammatory bowel disease. Nat Immunol 2019;20:970-979.

7. DeGruttola AK, Low D, Mizoguchi A, Mizoguchi E. Current understanding of dysbiosis in disease in human and animal models. Inflamm Bowel Dis 2016;22:1137-1150.

8. Shanahan F. The colonic microbiota in health and disease. Curr Opin Gastroenterol 2013;29:49-54.

9. Knights D, Lassen KG, Xavier RJ. Advances in inflammatory bowel disease pathogenesis: linking host genetics and the microbiome. Gut 2013;62:1505-1510.

10. Mizoguchi A. Animal models of inflammatory bowel disease. Prog Mol Biol Transl Sci 2012;105:263-320.

11. Anderson CA, Boucher G, Lees CW, et al. Meta-analysis identifies 29 additional ulcerative colitis risk loci, increasing the number of confirmed associations to 47 . Nat Genet 2011 43:246-252.

12. Abraham C, Cho JH. Inflammatory bowel disease. N Engl J Med 2009;361:2066-2078.

13. Franke A, McGovern DP, Barrett JC, et al. Genome-wide meta-analysis increases to 71 the number of confirmed Crohn's disease susceptibility loci. Nat Genet 2010;42:1118-1125.

14. Khor B, Gardet A, Xavier RJ. Genetics and pathogenesis of inflammatory bowel disease. Nature 2011;474:307-317.

15. Glocker EO, Kotlarz D, Boztug K, et al. Inflammatory bowel disease and mutations affecting the interleukin-10 receptor. N Engl J Med 2009;361:2033-2045.

16. Shouval DS, Biswas A, Goettel JA, et al. Interleukin-10 receptor signaling in innate immune cells regulates mucosal immune tolerance and anti-inflammatory macrophage function. Immunity 2014;40:706-719.

17. Mizoguchi E, Mizoguchi A, Bhan AK. Insights from recent advances in animal models of inflammatory bowel disease. In: D’Amato M, Rioux JD, eds. Molecular genetics of inflammatory bowel disease. New York: Springer, 2013:45-83.

18. Wirtz S, Neufert C, Weigmann B, Neurath MF. Chemically induced mouse models of intestinal inflammation. Nat Protoc 2007;2:541-546.

19. Kawada M, Arihiro A, Mizoguchi E. Insights from advances in research of chemically induced experimental models of human inflammatory bowel disease. World J Gastroenterol 2007;13:5581-5593.

20. Okayasu I, Hatakeyama S, Yamada M, Ohkusa T, Inagaki Y, Nakaya R. A novel method in the induction of reliable experimental acute and chronic ulcerative colitis in mice. Gastroenterology 1990;98:694-702.

21. Morris GP, Beck PL, Herridge MS, Depew WT, Szewczuk MR, Wallace JL. Hapten-induced model of chronic inflammation and ulceration in the rat colon. Gastroenterology 1989;96: 795-803.

22. Neurath MF, Fuss I, Kelsall BL, Stüber E, Strober W. Antibod- 
ies to interleukin 12 abrogate established experimental colitis in mice. J Exp Med 1995;182:1281-1290.

23. Alex P, Zachos NC, Nguyen T, et al. Distinct cytokine patterns identified from multiplex profiles of murine DSS and TNBSinduced colitis. Inflamm Bowel Dis 2009;15:341-352.

24. Boirivant M, Fuss IJ, Chu A, Strober W. Oxazolone colitis: a murine model of T helper cell type 2 colitis treatable with antibodies to interleukin 4. J Exp Med 1998;188:1929-1939.

25. MacPherson BR, Pfeiffer CJ. Experimental production of diffuse colitis in rats. Digestion 1978;17:135-150.

26. Dieleman LA, Elson CO, Tennyson GS, Beagley KW. Kinetics of cytokine expression during healing of acute colitis in mice. Am J Physiol. 1996 Jul;271(1 Pt 1):G130-G136.

27. Yamada T, Deitch E, Specian RD, Perry MA, Sartor RB, Grisham MB. Mechanisms of acute and chronic intestinal inflammation induced by indomethacin. Inflammation 1993;17:641662.

28. Lee WT, Yin XM, Vitetta ES. Functional and ontogenetic analysis of murine CD45Rhi and CD45Rlo CD4+ T cells. J Immunol 1990;144:3288-3295.

29. Powrie F, Leach MW, Mauze S, Caddle LB, Coffman RL. Phenotypically distinct subsets of CD4+ T cells induce or protect from chronic intestinal inflammation in C. B-17 scid mice. Int Immunol 1993;5:1461-1471.

30. Morrissey PJ, Charrier K, Braddy S, Liggitt D, Watson JD. CD4+ T cells that express high levels of CD45RB induce wasting disease when transferred into congenic severe combined immunodeficient mice: disease development is prevented by cotransfer of purified CD4+ T cells. J Exp Med 1993;178:237-244.

31. Ostanin DV, Bao J, Koboziev I, et al. T cell transfer model of chronic colitis: concepts, considerations, and tricks of the trade. Am J Physiol Gastrointest Liver Physiol 2009;296:G135G146.

32. Sundberg JP, Elson CO, Bedigian H, Birkenmeier EH. Spontaneous, heritable colitis in a new substrain of $\mathrm{C} 3 \mathrm{H} / \mathrm{HeJ}$ mice. Gastroenterology 1994;107:1726-1735.

33. Bristol IJ, Farmer MA, Cong Y, et al. Heritable susceptibility for colitis in mice induced by IL-10 deficiency. Inflamm Bowel Dis 2000;6:290-302.

34. Kosiewicz MM, Nast CC, Krishnan A, et al. Th1-type responses mediate spontaneous ileitis in a novel murine model of Crohn's disease. J Clin Invest 2001;107:695-702.

35. Bamias G, Martin C, Mishina M, et al. Proinflammatory effects of TH2 cytokines in a murine model of chronic small intestinal inflammation. Gastroenterology 2005;128:654-666. 36. Hugot JP, Chamaillard M, Zouali H, et al. Association of
NOD2 leucine-rich repeat variants with susceptibility to Crohn's disease. Nature 2001;411:599-603.

37. Duerr RH, Taylor KD, Brant SR, et al. A genome-wide association study identifies IL23R as an inflammatory bowel disease gene. Science 2006;314:1461-1463.

38. Brand S. Crohn's disease: Thl, Thl7 or both? The change of a paradigm: new immunological and genetic insights implicate Th17 cells in the pathogenesis of Crohn's disease. Gut 2009;58:1152-1167.

39. Mizoguchi A, Mizoguchi E. Animal models of IBD: linkage to human disease. Curr Opin Pharmacol 2010;10:578-587.

40. Kuballa P, Huett A, Rioux JD, Daly MJ, Xavier RJ. Impaired autophagy of an intracellular pathogen induced by a Crohn's disease associated ATG16L1 variant. PLoS One 2008;3:e3391.

41. Saitoh T, Fujita N, Jang MH, et al. Loss of the autophagy protein Atg16L1 enhances endotoxin-induced IL-1beta production. Nature 2008;456:264-268.

42. Hitotsumatsu O, Ahmad RC, Tavares R, et al. The ubiquitinediting enzyme A20 restricts nucleotide-binding oligomerization domain containing 2-triggered signals. Immunity 2008;28:381-390.

43. Mizoguchi A, Mizoguchi E, Chiba C, et al. Cytokine imbalance and autoantibody production in $\mathrm{T}$ cell receptor-alpha mutant mice with inflammatory bowel disease. J Exp Med 1996;183:847-856.

44. Mizoguchi A, Mizoguchi E, Chiba C, Bhan AK. Role of appendix in the development of inflammatory bowel disease in TCR-alpha mutant mice. J Exp Med 1996;184:707-715.

45. Bhan AK, Mizoguchi E, Smith RN, Mizoguchi A. Colitis in transgenic and knockout animals as models of human inflammatory bowel disease. Immunol Rev 1999;169:195-207.

46. Iijima H, Takahashi I, Kishi D, et al. Alteration of interleukin 4 production results in the inhibition of $\mathrm{T}$ helper type 2 celldominated inflammatory bowel disease in $\mathrm{T}$ cell receptor alpha chain-deficient mice. J Exp Med 1999;190:607-615.

47. Mizoguchi A, Mizoguchi E, Saubermann LJ, Higaki K, Blumberg RS, Bhan AK. Limited CD4 T-cell diversity associated with colitis in T-cell receptor alpha mutant mice requires a $\mathrm{T}$ helper 2 environment. Gastroenterology 2000;119:983-995.

48. Morgan NV, Goddard S, Cardno TS, et al. Mutation in the TCR $\alpha$ subunit constant gene (TRAC) leads to a human immunodeficiency disorder characterized by a lack of TCR $\alpha \beta+$ T cells. J Clin Invest 201 1;121:695-702.

49. Dianda L, Hanby AM, Wright NA, Sebesteny A, Hayday AC, Owen MJ. T cell receptor-alpha beta-deficient mice fail to develop colitis in the absence of a microbial environment. Am J 
Pathol 1997;150:91-97.

50. Chin EY, Dangler CA, Fox JG, Schauer DB. Helicobacter hepaticus infection triggers inflammatory bowel disease in $\mathrm{T}$ cell receptor alphabeta mutant mice. Comp Med 2000;50:586594.

51. Burich A, Hershberg R, Waggie K, et al. Helicobacter-induced inflammatory bowel disease in IL-10- and T cell-deficient mice. Am J Physiol Gastrointest Liver Physiol 2001;281:G764G778.

52. Gaskins HR, Vondrak-Juergens GL, McCracken BA, Woolsey JH. Specific-pathogen-free conditions enhance inflammatory bowel disease in T-cell receptor knockout, but not C3H/ HeJBir mice. Lab Anim Sci 1997;47:650-655.

53. Shimomura Y, Mizoguchi E, Sugimoto K, et al. Regulatory role of B-1 B cells in chronic colitis. Int Immunol 2008;20:729737.

54. Mizoguchi A, Bhan AK. A case for regulatory B cells. J Immunol 2006;176:705-710.

55. Mizoguchi A, Mizoguchi E, Takedatsu H, Blumberg RS, Bhan AK. Chronic intestinal inflammatory condition generates IL10-producing regulatory B cell subset characterized by CD1d upregulation. Immunity 2002;16:219-230.

56. Sugimoto K, Ogawa A, Shimomura Y, Nagahama K, Mizoguchi A, Bhan AK. Inducible IL-12-producing B cells regulate Th2-mediated intestinal inflammation. Gastroenterology 2007;133:124-136.

57. Leiper K, Martin K, Ellis A, et al. Randomised placebo-controlled trial of rituximab (anti-CD20) in active ulcerative colitis. Gut 2011;60:1520-1526.

58. Goetz M, Atreya R, Ghalibafian M, Galle PR, Neurath MF. Exacerbation of ulcerative colitis after rituximab salvage therapy. Inflamm Bowel Dis 2007;13:1365-1368.

59. Ardelean DS, Gonska T, Wires S, et al. Severe ulcerative colitis after rituximab therapy. Pediatrics 2010;126:e243-e246.

60. Ananthakrishnan AN, Higuchi LM, Huang ES, et al. Aspirin, nonsteroidal anti-inflammatory drug use, and risk for Crohn disease and ulcerative colitis: a cohort study. Ann Intern Med 2012;156:350-359.

61. Matharu KS, Mizoguchi E, Cotoner CA, et al. Toll-like receptor 4-mediated regulation of spontaneous Helicobacter-dependent colitis in IL-10-deficient mice. Gastroenterology 2009;137:1380-1390.

62. Sellon RK, Tonkonogy S, Schultz M, et al. Resident enteric bacteria are necessary for development of spontaneous colitis and immune system activation in interleukin-10-deficient mice. Infect Immun 1998;66:5224-5231.
63. Hoentjen F, Harmsen HJ, Braat H, et al. Antibiotics with a selective aerobic or anaerobic spectrum have different therapeutic activities in various regions of the colon in interleukin 10 gene deficient mice. Gut 2003;52:1721-1727.

64. Davidson NJ, Hudak SA, Lesley RE, Menon S, Leach MW, Rennick DM. IL-12, but not IFN-gamma, plays a major role in sustaining the chronic phase of colitis in IL-10-deficient mice. J Immunol 1998;161:3143-3149.

65. Hackam DG, Redelmeier DA. Translation of research evidence from animals to humans. JAMA 2006;296:1731-1732.

66. Mak IW, Evaniew N, Ghert M. Lost in translation: animal models and clinical trials in cancer treatment. Am J Transl Res 2014;6:114-118.

67. Fujii Y, Sengoku T. Effects of the Janus kinase inhibitor CP690550 (tofacitinib) in a rat model of oxazolone-induced chronic dermatitis. Pharmacology 2013;91:207-213.

68. Beattie DT, Pulido-Rios MT, Shen F, et al. Intestinally-restricted Janus kinase inhibition: a potential approach to maximize the therapeutic index in inflammatory bowel disease therapy. J Inflamm (Lond) 2017;14:28.

69. Sandborn WJ, Ghosh S, Panes J, et al. A phase 2 study of tofacitinib, an oral Janus kinase inhibitor, in patients with Crohn's disease. Clin Gastroenterol Hepatol 2014;12:1485-1493.

70. Menet CJ, Fletcher SR, van Lommen G, et al. Triazolopyridines as selective JAK1 inhibitors: from hit identification to GLPG0634. J Med Chem 2014;57:9323-9342.

71. Namour F, Diderichsen PM, Cox E, et al. Pharmacokinetics and pharmacokinetic/pharmacodynamic modeling of Filgotinib (GLPG0634), a selective JAK1 inhibitor, in support of phase IIB dose selection. Clin Pharmacokinet 2015;54:859874.

72. Parmentier JM, Voss J, Graff C, et al. In vitro and in vivo characterization of the JAK1 selectivity of upadacitinib (ABT494). BMC Rheumatol 2018;2:23.

73. Nielsen OH, Li Y, Johansson-Lindbom B, Coskun M. Sphingosine-1-phosphate signaling in inflammatory bowel disease. Trends Mol Med 2017;23:362-374.

74. Karuppuchamy T, Behrens EH, González-Cabrera P, et al. Sphingosine-1-phosphate receptor-1 ( $\mathrm{S} 1 \mathrm{P}(1))$ is expressed by lymphocytes, dendritic cells, and endothelium and modulated during inflammatory bowel disease. Mucosal Immunol 2017;10:162-171.

75. Scott FL, Clemons B, Brooks J, et al. Ozanimod (RPC1063) is a potent sphingosine-1-phosphate receptor-1 (S1P1) and receptor-5 (S1P5) agonist with autoimmune disease-modifying activity. Br J Pharmacol 2016;173:1778-1792. 
76. Peyrin-Biroulet L, Panés J, Chiorean M, et al. Histological remission and mucosal healing in a randomised, placebo-controlled, phase 2 study of etrasimod in patients with moderately to severely active ulcerative colitis. J Crohns Colitis 2019;13:S6.

77. Sugiura T, Kageyama S, Andou A, et al. Oral treatment with a novel small molecule alpha 4 integrin antagonist, AJM300, prevents the development of experimental colitis in mice. J Crohns Colitis 2013; 7:e533-e542.

78. Yoshimura N, Watanabe M, Motoya S, et al. Safety and efficacy of AJM300, an oral antagonist of $\alpha 4$ integrin, in induction therapy for patients with active ulcerative colitis. Gastroenterology 2015;149:1775-1783.

79. Wermers JD, McNamee EN, Wurbel MA, Jedlicka P, RiveraNieves J. The chemokine receptor CCR9 is required for the Tcell-mediated regulation of chronic ileitis in mice. Gastroenterology 2011;140:1526-1535.

80. Keshav S, Vaňásek T, Niv Y, et al. A randomized controlled trial of the efficacy and safety of CCX282-B, an orally-administered blocker of chemokine receptor CCR9, for patients with Crohn's disease. PLoS One 2013;8:e60094.

81. Powrie F, Leach MW, Mauze S, Menon S, Caddle LB, Coffman RL. Inhibition of Th1 responses prevents inflammatory bowel disease in scid mice reconstituted with CD45RBhi CD4+ T cells. Immunity 1994;1:553-562.

82. Olson AD, DelBuono EA, Bitar KN, Remick DG. Antiserum to tumor necrosis factor and failure to prevent murine colitis. J Pediatr Gastroenterol Nutr 1995;21:410-418.

83. Rennick DM, Fort MM, Davidson NJ. Studies with IL-10-/mice: an overview. J Leukoc Biol 1997;61:389-396.

84. Berg DJ, Davidson N, Kühn R, et al. Enterocolitis and colon cancer in interleukin-10-deficient mice are associated with aberrant cytokine production and CD4(+) TH1-like responses. J Clin Invest 1996;98:1010-1020.

85. Heller F, Fuss IJ, Nieuwenhuis EE, Blumberg RS, Strober W. Oxazolone colitis, a Th2 colitis model resembling ulcerative colitis, is mediated by IL-13-producing NK-T cells. Immunity 2002;17:629-638.

86. Hoving JC, Kirstein F, Nieuwenhuizen NE, et al. B cells that produce immunoglobulin E mediate colitis in BALB/c mice. Gastroenterology 2012;142:96-108.

87. Davies SC, Nguyen TM, Parker CE, MacDonald JK, Jairath V, Khanna R. Anti-IL-12/23p40 antibodies for maintenance of remission in Crohn's disease. Cochrane Database Syst Rev 2019;12:CD012804.

88. Verstockt B, Ferrante M, Vermeire S, van Assche G. New treat- ment options for inflammatory bowel diseases. J Gastroenterol 2018;53:585-590.

89. Atreya R, Mudter J, Finotto S, et al. Blockade of interleukin 6 trans signaling suppresses T-cell resistance against apoptosis in chronic intestinal inflammation: evidence in Crohn disease and experimental colitis in vivo. Nat Med 2000;6:583588.

90. Yamamoto M, Yoshizaki K, Kishimoto T, Ito H. IL-6 is required for the development of Thl cell-mediated murine colitis. J Immunol 2000;164:4878-4882.

91. Park SC, Jeen YT. Anti-integrin therapy for inflammatory bowel disease. World J Gastroenterol 2018;24:1868-1880.

92. Zundler S, Schillinger D, Fischer A, et al. Blockade of $\alpha \mathrm{E} \beta 7$ integrin suppresses accumulation of CD8(+) and Th9 lymphocytes from patients with IBD in the inflamed gut in vivo. Gut 2017;66:1936-1948.

93. Khan I, Ullah N, Zha L, et al. Alteration of gut microbiota in inflammatory bowel disease (IBD): cause or consequence? IBD treatment targeting the gut microbiome. Pathogens 2019; 8:E126.

94. Burrello C, Giuffrè MR, Macandog AD, et al. Fecal microbiota transplantation controls murine chronic intestinal inflammation by modulating immune cell functions and gut microbiota composition. Cells 2019;8:E517.

95. Burrello C, Garavaglia F, Cribiù FM, et al. Therapeutic faecal microbiota transplantation controls intestinal inflammation through IL10 secretion by immune cells. Nat Commun 2018; 9:5184.

96. McCoy KD, Geuking MB, Ronchi F. Gut microbiome standardization in control and experimental mice. Curr Protoc Immunol 2017;117:23.1.1-23.1.13.

97. Koboziev I, Jones-Hall Y, Valentine JF, Webb CR, Furr KL, Grisham MB. Use of humanized mice to study the pathogenesis of autoimmune and inflammatory diseases. Inflamm Bowel Dis 2015;21:1652-1673.

98. Goettel JA, Gandhi R, Kenison JE, et al. AHR activation is protective against colitis driven by $\mathrm{T}$ cells in humanized mice. Cell Rep 2016;17:1318-1329.

99. Goettel JA, Kotlarz D, Emani R, et al. Low-dose interleukin-2 ameliorates colitis in a preclinical humanized mouse model. Cell Mol Gastroenterol Hepatol 2019;8:193-195.

100. Kozlowski C, Jeet S, Beyer J, et al. An entirely automated method to score DSS-induced colitis in mice by digital image analysis of pathology slides. Dis Model Mech 2013;6:855-865.

101. Romagnoni A, Jégou S, van Steen K, Wainrib G, Hugot JP; International Inflammatory Bowel Disease Genetics Consor- 
tium (IIBDGC). Comparative performances of machine learning methods for classifying Crohn disease patients using genome-wide genotyping data. Sci Rep 2019;9:10351.

102. Moran CJ, Klein C, Muise AM, Snapper SB. Very early-onset inflammatory bowel disease: gaining insight through focused discovery. Inflamm Bowel Dis 2015;21:1166-1175.

103. Shin W, Kim HJ. Intestinal barrier dysfunction orchestrates the onset of inflammatory host-microbiome cross-talk in a human gut inflammation-on-a-chip. Proc Natl Acad Sci U S A 2018;115:E10539-E10547.
104. Xu P, Becker H, Elizalde M, Masclee A, Jonkers D. Intestinal organoid culture model is a valuable system to study epithelial barrier function in IBD. Gut 2018;67:1905-1906.

105. Sarvestani SK, Signs SA, Lefebvre V, et al. Cancer-predicting transcriptomic and epigenetic signatures revealed for ulcerative colitis in patient-derived epithelial organoids. Oncotarget 2018;9:28717-28730.

106. Yoo JH, Donowitz M. Intestinal enteroids/organoids: a novel platform for drug discovery in inflammatory bowel diseases. World J Gastroenterol 2019;25:4125-4147. 